\title{
Variation in food group and nutrient intake with day of the week in an elderly population
}

\author{
BY SUSAN MAISEY ${ }^{1}$, JULIE LOUGHRIDGE ${ }^{2}$, SUSAN SOUTHON ${ }^{2}$ \\ AND ROBERT FULCHER ${ }^{1}$ \\ ${ }^{1}$ Department of Medicine for the Elderly, West Norwich Hospital, Bowthorpe Road, \\ Norwich NR2 $3 T U$ \\ ${ }^{2}$ Institute for Food Research, Norwich Research Park, Colney, Norwich NR4 7UA
}

(Received 12 February 1994-Revised 2 May 1994-Accepted 24 June 1994)

\begin{abstract}
The present paper is an analysis of 138 5- or 7-d diet diaries collected from a free-living population of people aged 68-90 years in Norwich. Men had higher intakes than women of energy and most nutrients, but patterns of variation across the week were similar for both sexes. Intakes of meat, meat products, fish and vegetables varied across the week both in frequency and amount eaten, but the other main food groups showed no significant variation. Alcohol was taken more frequently at weekends but the amount did not vary significantly. Intakes of energy, protein and many micronutrients varied significantly with day of the week, with increased intake at weekends, especially of vegetable-derived micronutrients on Sundays, and generally decreased intake on Mondays and Fridays. Nutrient densities of carotene, retinol equivalents, folate, vitamin $\mathrm{C}$, pantothenate and $\mathrm{Zn}$ were all highest on Sundays, providing further evidence of variation of diet quality on different days of the week.
\end{abstract}

Dietary intake: Intra-subject variation: Elderly.

The proportions of old and very old people in the population of the UK have increased with improved survival in the older age-groups during this century and are expected to rise further (Department of Health, 1992a). Disability and morbidity increase with age, and there are proven and suspected links between malnutrition and chronic disease. For these reasons there is currently much interest in the nutrition of elderly people and the Department of Health $(1992 b)$ has recommended research into nutrient intakes and nutrient requirements of this sector of the population.

While it is accepted that many days of dietary recording are required to estimate accurately the habitual nutrient intake of an individual, fewer days of recording for each subject are needed if it is the population rather than the individual which is to be assessed (Bingham, 1987). Prolonged dietary recording can be arduous for the subject, requiring frequent interviewer contact to ensure generation of high-quality data, and in large studies resources may not allow a full week's assessment for each individual. There is little published information about whether there are differences in nutrient intake associated with day of the week in the elderly. Limited information on younger, working adults suggests that total energy intake is increased at weekends, and that other observed differences in nutrient intakes are due to variation in overall food consumption rather than diet quality (Beaton et al. 1979, 1983; Gibson et al. 1985; Thomson et al. 1988; de Castro, 1991; Tarasuk \& Beaton, 1992). However, conclusions drawn from studies of younger people may not be applicable to older, retired populations due to possible differences in lifestyle and dietary habits. 
In 1990 a collaborative study was set up in Norwich by the Institute of Food Research, Norwich Health Authority and the Department of Medicine for the Elderly, West Norwich Hospital, to address the problem of lack of comparative information on the elderly and younger age-groups in the same community. Nutrient intakes and anthropometric and biochemical indices were also examined with the aim of relating intake to outcome measures of nutritional status in the elderly. The present paper is an analysis of data generated by this study to determine whether there are differences in food and nutrient intakes on different days of the week in an elderly population living at home.

\section{MATERIALS AND METHODS}

The study protocol was approved by the Norwich Health Authority and the Institute of Food Research Ethics Committees before subject recruitment.

\section{Subjects}

Elderly subjects were randomly selected from the age-sex registers of two general practice (GP) surgeries in Norwich, after exclusion of those addresses known to be institutions for the care of dependent elderly people, and were invited by letter to take part in the study. Response rates at different ages are shown in Fig. 1 and showed a drop from $67 \%$ of those aged under 70 years to $20 \%$ of those aged over 85 years. Recruitment took place in two phases, the first consisting of a group aged 68-73 years (young elderly) and the second consisting of subjects aged 74 years and over (old elderly). Due to the poor response rate of people in the older age-groups the second phase was extended, another random selection being made from the GP registers and more invitations sent out. The final age-sex distribution achieved is shown in Figs 2 and 3. A total of 145 subjects were recruited (seventy-four young elderly and seventy-one old elderly). Descriptions of the study population (age-group, sex, weight and percentage living alone) are shown in Table 1 and social class distribution in Fig. 4. Only one subject received meals on wheels. The subjects were seen initially either in their local GP surgery or at home according to preference. After explanation of the study and the signing of a consent form by the subject, demographic, social and medical information was elicited and anthropometric measurements made. A $12 \mathrm{~h}$ fasting blood sample was taken at a second visit and arrangement made for a dietary interviewer to call at the subject's home.

\section{Measurement of dietary intake}

The dietary recording procedure was explained and illustrated in detail in the familiar surroundings of the subject's own home, as this was thought to be more conducive to understanding and compliance in this age-group. The presence of the subject's partner or relative, where appropriate, was encouraged by the fieldworker, to ensure that the procedures were understood and executed as thoroughly as possible. This interview was conducted the day before commencing the recording period, wherever possible, so that the procedures and instructions would be remembered. The subjects were shown how to record recipes, ready meals, foods eaten out of the home, and plate waste. An example menu record, time-table of recording dates and an instruction booklet were issued as an aidememoire. Menu records were provided, a new one for each day, consisting of single tabulated A4 sheets with sections for breakfast, morning snacks, lunch, afternoon snacks, tea or dinner and evening snacks, and with columns for portion size and waste. Subjects were encouraged to weigh their food, in units of their choice, wherever possible, using their own household scales. Household measures were also acceptable as a means of assessing quantity or volume. 


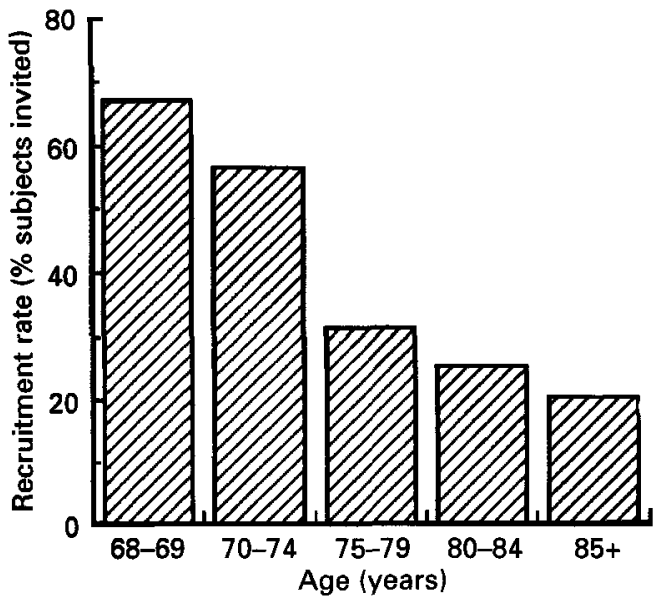

Fig. 1. Recruitment rate (as a percentage of those invited to participate) and age-group. For details of recruitment procedure, see p. 360 .

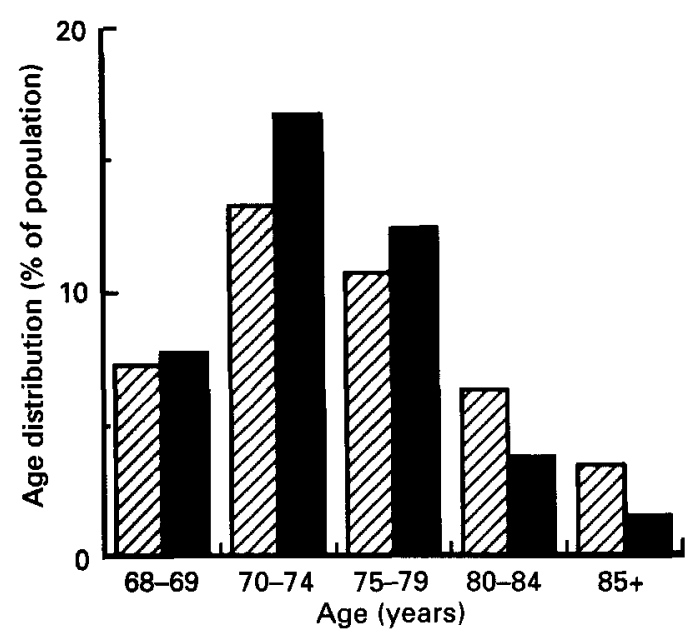

Fig. 2. Age distribution of study men compared with local population data. ( 7 ), Men as a percentage of the population aged over 68 years calculated from Office of Population Censuses and Surveys (1990) media estimates for Norwich Health District. ( $\square$ ), Men as a percentage of the study population. For details of subjects and procedures, see Table 1 and p. 360 .

The young elderly group completed a $7 \mathrm{~d}$ semi-weighed intake record, for the most part over consecutive days but always including all five weekdays and both weekend days. Subjects were visited by a trained fieldworker two to three times during the assessment period (including initial and final visit), although the number of visits was left to the fieldworker's discretion, depending on each subject's recording ability. Menu records, scales and types of household measures used were checked, any additional or missing information obtained, menu records annotated and completed records collected. Of this group, $31 \%$ weighed all their food, $57 \%$ used household measures and $12 \%$ used a combination of methods. 


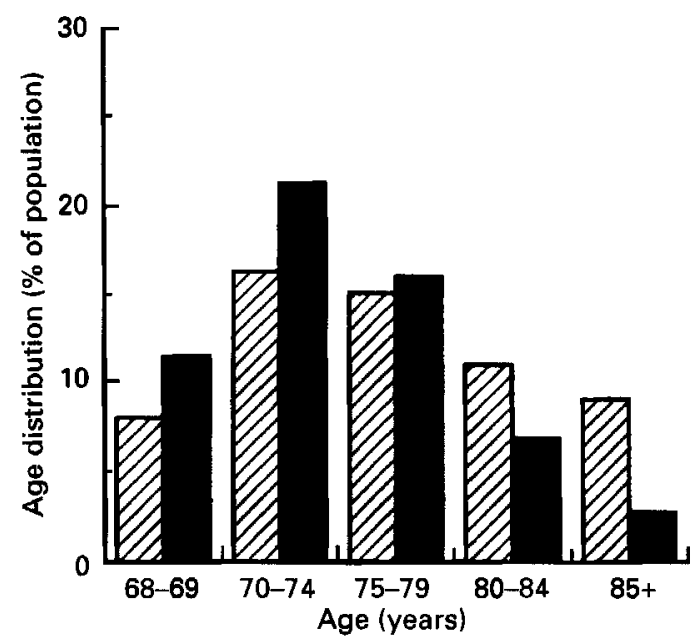

Fig. 3. Age distribution of study women compared with local population data. $(\square)$, Women as a percentage of the population aged over 68 years calculated from Office of Population Censuses and Surveys (1990) media estimates for Norwich Health District. ( $\square$ ), Women as a percentage of the study population. For details of subjects and procedures, see Table 1 and p. 360 .

Table 1. Description of study population

(Mean values with their standard errors and range)

\begin{tabular}{|c|c|c|c|c|c|c|c|c|c|}
\hline & \multirow[b]{3}{*}{$n$} & & & & & & & \multicolumn{2}{|c|}{ Percentage living alone } \\
\hline & & \multicolumn{3}{|c|}{ Height (m) } & \multicolumn{3}{|c|}{ Wt $(\mathrm{kg})$} & \multirow{2}{*}{$\begin{array}{l}\text { Present } \\
\text { study }\end{array}$} & \multirow{2}{*}{$\begin{array}{l}\text { Values from } \\
\text { GHS for } \\
\text { comparison }\end{array}$} \\
\hline & & Mean & $\mathrm{SE}$ & Range & Mean & $\mathrm{SE}$ & Range & & \\
\hline \multicolumn{10}{|c|}{ Young elderly (age 68-73 years) } \\
\hline Men & 32 & 1.67 & 0.01 & $1.50-1.78$ & $72 \cdot 4$ & $2 \cdot 0$ & $46-92$ & 13 & 18 \\
\hline Women & 42 & 1.57 & 0.01 & $1.41-1.71$ & $63 \cdot 5$ & 1.6 & $45-84$ & 38 & 37 \\
\hline \multicolumn{10}{|c|}{ Old elderly (age $74-90$ years) } \\
\hline Men & 28 & 1.68 & 0.01 & $1.51-1.84$ & $70 \cdot 5$ & $2 \cdot 0$ & $47 \cdot 5-92$ & 18 & 32 \\
\hline Women & 43 & $1 \cdot 55$ & 0.01 & $1 \cdot 41-1 \cdot 72$ & $61 \cdot 1$ & 1.5 & $41-82$ & 44 & 60 \\
\hline
\end{tabular}

GHS, General Household Survey 1991 (Office of Population Censuses and Surveys, 1993).

The old elderly completed a $5 \mathrm{~d}$ menu record similar to that given to the young elderly group. Three weekdays and both weekend days of the same week were included. Subjects were visited three to four times over the period of dietary recording. In addition to the checks mentioned previously, subjects were asked to recall their activities and what they had eaten over the past $24-48 \mathrm{~h}$. Considerably more interviewer prompting and extensive annotation of the completed menu records was required for this age-group. Also, interview time tended to be longer, as many lived alone and valued the fieldworker as a social caller. Only $7 \%$ of this group weighed all their food, $3 \%$ weighed some of their food and the remaining $90 \%$ used household measures.

Dietary information was collected from approximately five young elderly subjects per week between mid-May and mid-August 1990, and from approximately three old elderly subjects per week between November 1990 and May 1991, excluding the 2 weeks before and 2 weeks after Christmas. 


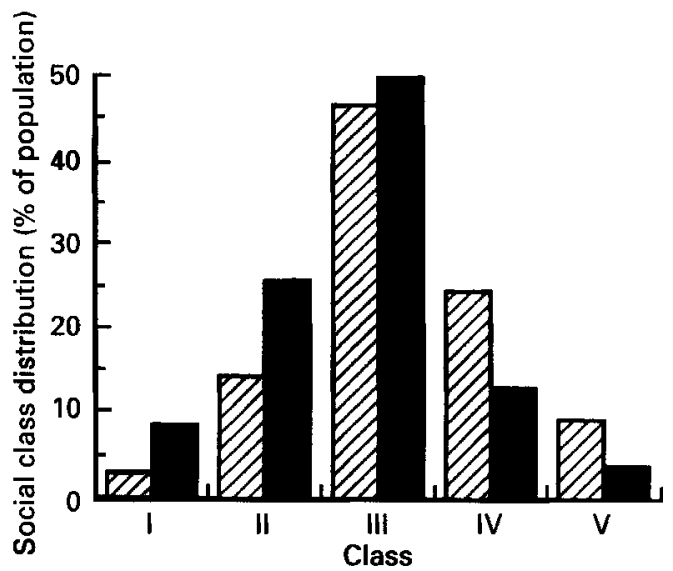

Fig. 4. Social class distribution of study subjects $(\mathbb{C}$ ) compared with social class of those aged over 65 years calculated from tables in General Household Survey 1985 (Office of Population Censuses and Surveys, 1987; 7 ). For details of subjects and procedures, see Table 1 and p. 360 .

The same fieldworkers were used for both phases of dietary recording. Subjects were visited by the same fieldworker on each occasion and were given a telephone number to contact in the event of queries arising on days when a visit from a fieldworker was not planned.

\section{Dietary coding and calculation of nutrient intakes}

The menu records were coded and checked by an experienced coder, using the extensive Institute of Food Research nutrient database which comprises McCance and Widdowson's The Composition of Foods, 4th edition (Paul \& Southgate, 1978), together with Immigrant Foods (Tan et al. 1985), additional foods (Wiles et al. 1980), Cereals and Cereal Products (Holland et al. 1988) and Milk and Milk Products (Holland et al. 1989); values of portion sizes, standard weights of branded foods and composition of composite dishes collected from previous dietary intake studies (J. M. Loughridge and A. Walker, unpublished results) were also used. Additional values for unquantified foods were obtained using Food Portion Sizes (Crawley, 1988). It should be noted here that the dietary data were collected and collated before the publication of either The Composition of Foods, 5th edition, or the 5 th edition supplements.

The coded data from the menu records were entered into individual files on the IFR mini computer (VAX 4100, VMS 5.5-2). The data were entered twice, as a routine procedure, once by the coder and independently by a data typist; a 'differences' program, written in Fortran, was then run on each data set as a cross-check, to eliminate typing or data-entry errors. These files were then stored in an Oracle relational database (Oracle Corporation UK Ltd, Bracknell, Berks) which also contained the standard UK food composition data.

\section{Statistical methods}

Intake data for food groups and nutrients were calculated in the Oracle database and then exported with associated information (subject number, sex, day of the week and sequence number in days of recording), and analysis carried out using Minitab, a statistical spreadsheet (Minitab Inc., State College, PA, USA). 
Initially data were examined to determine whether obvious differences in patterns of intake existed between men and women and between younger and older groups. While men in general had greater intakes than women of energy and most nutrients, the pattern of variation across the week was similar for men and women, except in the case of alcohol. The proportion of men relative to women who kept a diary on any one day was very similar across the week $\left(\chi^{2} 0 \cdot 648\right.$, df $\left.6, P=0.9955\right)$. Intakes and patterns were similar for younger and older age-groups. It was considered, therefore, to be valid to pool the sexes and agegroups for increased power in the analysis.

A general linear model (GLM) which performs a two-way analysis of variance for an unbalanced design, with unequal numbers of observations for each factor, was then applied to the data to test for effect of various different factors on intake. The resulting residuals were checked for normality and equality of variances. Where the data were found to be poorly conditioned to the analysis the original data were $\log _{10}$ transformed. Following $\log _{10}$ transformation the GLM was repeated and the residuals re-analysed. In most cases this resulted in normally-distributed residuals and equal variances, but in the cases of a few of the nutrients it was thought safer to use the Kruskal-Wallis test, a less sensitive but distribution-independent non-parametric equivalent to a one-way analysis of variance based on the ranks of the data. Means are quoted for untransformed data, geometric means for $\log _{10}$ transformed data, and medians where the use of the Kruskal-Wallis method was required. Confidence intervals $(95 \%)$ have been calculated for all these values.

Although periods of dietary recording were not all started on the same day, they were much more likely to begin on a Tuesday, Wednesday or Thursday than any other day. It was considered, therefore, that recording fatigue might be a confounding factor in the analysis, with less intake being reported at the end of the period of dietary recording, which would include disproportionate numbers of Saturdays, Sundays and Mondays. The GLM model was, therefore, first written to test for day and sequence number of record effect and any interaction. No evidence of recording fatigue or any training effect was found using this technique, and, therefore, sequence number was omitted from all further analysis.

For the next stage of analysis the GLM model was written to test for sex and day of the week effects and any interaction. The means or geometric means for the two sexes were calculated from this model. There were no sex $x$ day interactions. Finally, the GLM model was written to test for day-of-the-week effect blocked for subject. Calculated means or geometric means for days of the week were derived from this model.

Where the Kruskal-Wallis test had to be used, sex and day effect were separately tested and the assumption was made that there was no interaction. It was not possible to do an analysis blocked by subject using this method so there is a considerable loss of sensitivity compared with data which could be analysed using GLM.

Where highly significant day-of-the-week effects were found, the data for those who lived alone and those who lived with others were separately analysed using GLM blocked for subject and results compared to determine whether living arrangements affected patterns of intake.

\section{RESULTS}

\section{Food group intake}

The percentage of subjects eating at least one item from a food group on a given day is shown in Table 2. The frequency of consumption of liver is not tabulated separately (it is included in either meat or meat products as appropriate) since during the $832 \mathrm{~d}$ diaries collected only twenty occurrences of the consumption of liver were recorded, none of which were on a Sunday or Monday. However, when liver was eaten it made a very large contribution to the total intake of many micronutrients. Table 3 shows the amount of food 
WEEKLY VARIATION IN ELDERLY DIETARY INTAKE

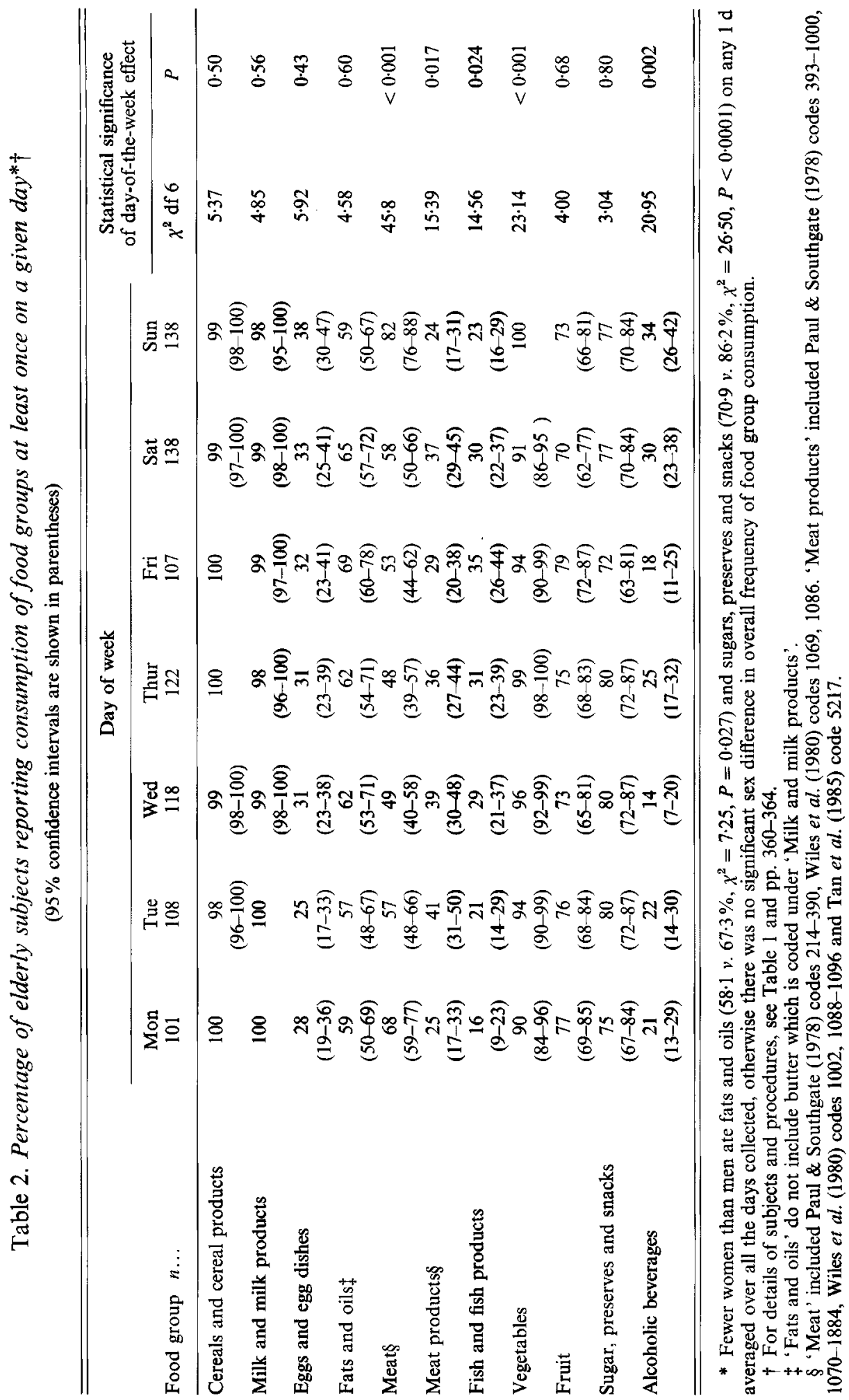


from each food group which was eaten on days when any consumption was reported. There was little variation across the week in the amount or frequency of consumption of cereals, milk, eggs, fats, fruit and sugars and snacks. However, meat, meat products, fish and vegetables varied across the week both in percentage of subjects reporting consumption and in amounts eaten.

\section{Nutrient intake}

Nutrient intake by sex and day of the week and the significance levels for sex and day-ofthe-week differences are shown in Tables 4-6.

\section{Macronutrients}

Total energy intake was highest at weekends and lowest on Mondays and Fridays and was closely paralleled by fat intake. The pattern of energy intake in those who lived alone was very similar to that in those who lived with others. Carbohydrate intake did not vary significantly across the week, but did form a significantly higher percentage contribution to energy intake on Mondays, due to the lower total energy, fat and protein intakes on that day. Protein intake was highest on Sundays and fat on Saturdays, but the percentage contribution to energy of these nutrients did not vary significantly during the week.

\section{Micronutrients}

$\mathrm{Zn}, \mathrm{S}$, pantothenate, biotin, nicotinic acid, vitamin $\mathrm{B}_{6}$ and vitamin $\mathrm{E}$ all showed similar patterns, with lowest intakes on Mondays and Fridays and highest on Sundays. Most of the variability of these nutrients across the week reflected variation in energy intake with only $\mathrm{Zn}(P=0.031)$ and pantothenate $(P=0.001)$ showing a significant day-of-the-week effect when expressed as amount of nutrient per MJ energy intake. The highest nutrient density for $\mathrm{Zn}$ and pantothenate was on Sunday.

$\mathrm{Cu}$ and vitamin $\mathrm{B}_{12}$ intakes were lowest on Mondays, but showed little variation for the rest of the week. Retinol intake showed no variation with day, but carotene intake was greatly increased on Sundays compared with all other days, and thus resulted in significant variation in retinol equivalent intake. Folate and vitamin $\mathrm{C}$ intakes were also highest by far on Sundays, in keeping with the increased vegetable intake already demonstrated. Identical patterns were seen for carotene, folate and vitamin $\mathrm{C}$ in those who lived alone compared with those who lived with other people.

Significant day-of-the-week differences remained for carotene $(P<0 \cdot 001)$, retinol equivalents $(P=0.008)$, folate $(P=0.022)$, vitamin $\mathrm{C}(P=0.017)$, and vitamin $\mathrm{B}_{12}(P=$ $0.017)$ when intakes were calculated as amount per $M J$, with the highest nutrient densities occurring on Sundays, except for vitamin $B_{12}$ (highest densities on Wednesdays).

The only instance where men and women exhibited clearly different patterns of intake was in relation to alcohol. A total of $37 \%$ of men and $55 \%$ of women reported no alcohol intake during the recording period. Alcoholic beverages were more frequently drunk on Saturdays and Sundays than the rest of the week by both sexes but men appeared to have higher alcohol intakes at the weekend, which was not the case for women. The data could not be satisfactorily transformed for the GLM and the assumption of no sex interaction in the Kruskal-Wallis test could not be made. The Kruskal-Wallis test was applied separately, therefore, to the male and female intakes and no significant day-of-the-week effect was found using this rather insensitive technique. When alcohol was taken, men had a median daily intake of $14.8 \mathrm{~g}$, which was significantly higher than the median of $10.4 \mathrm{~g}$ for women $(P=0.003)$. 


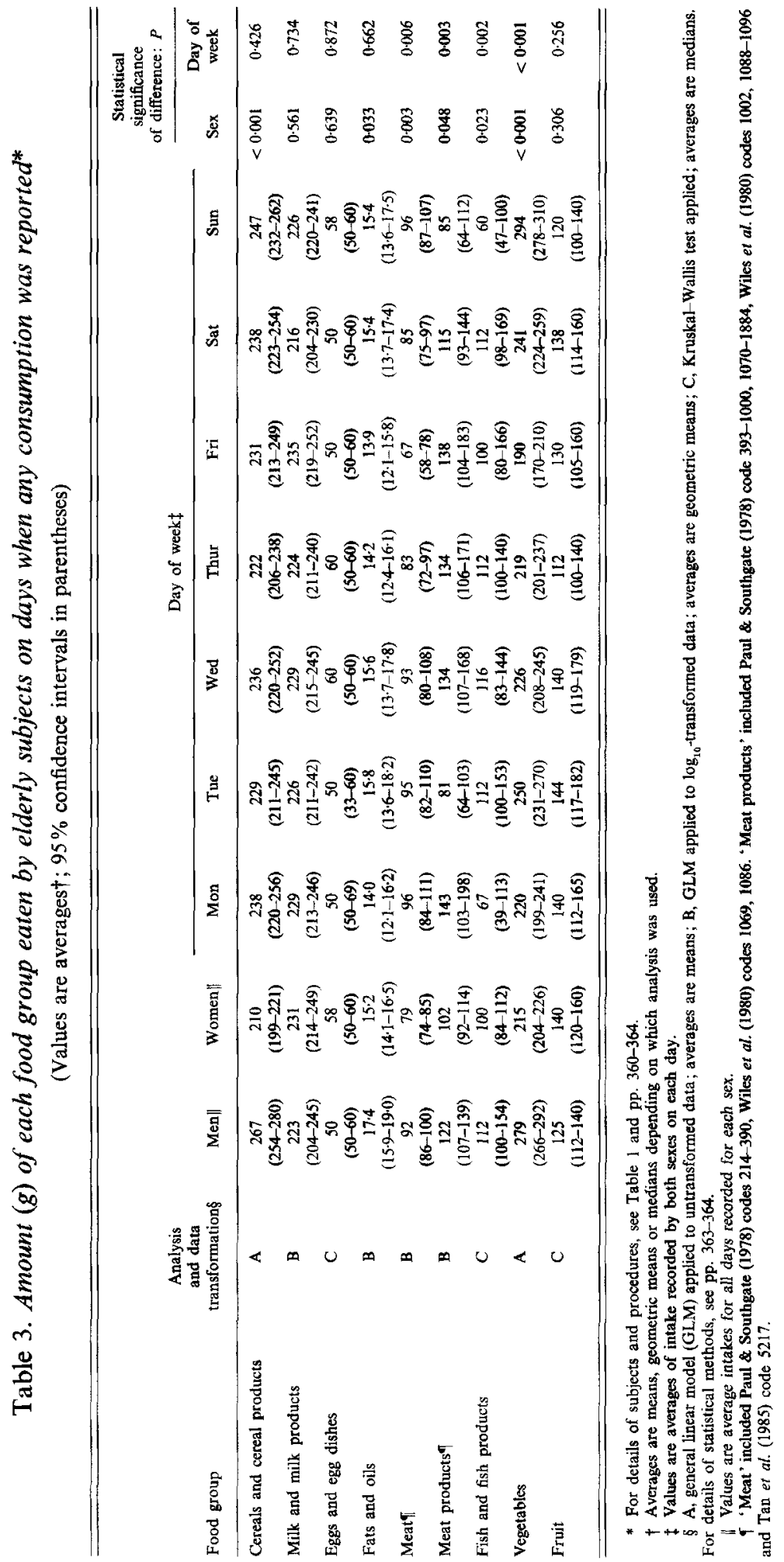




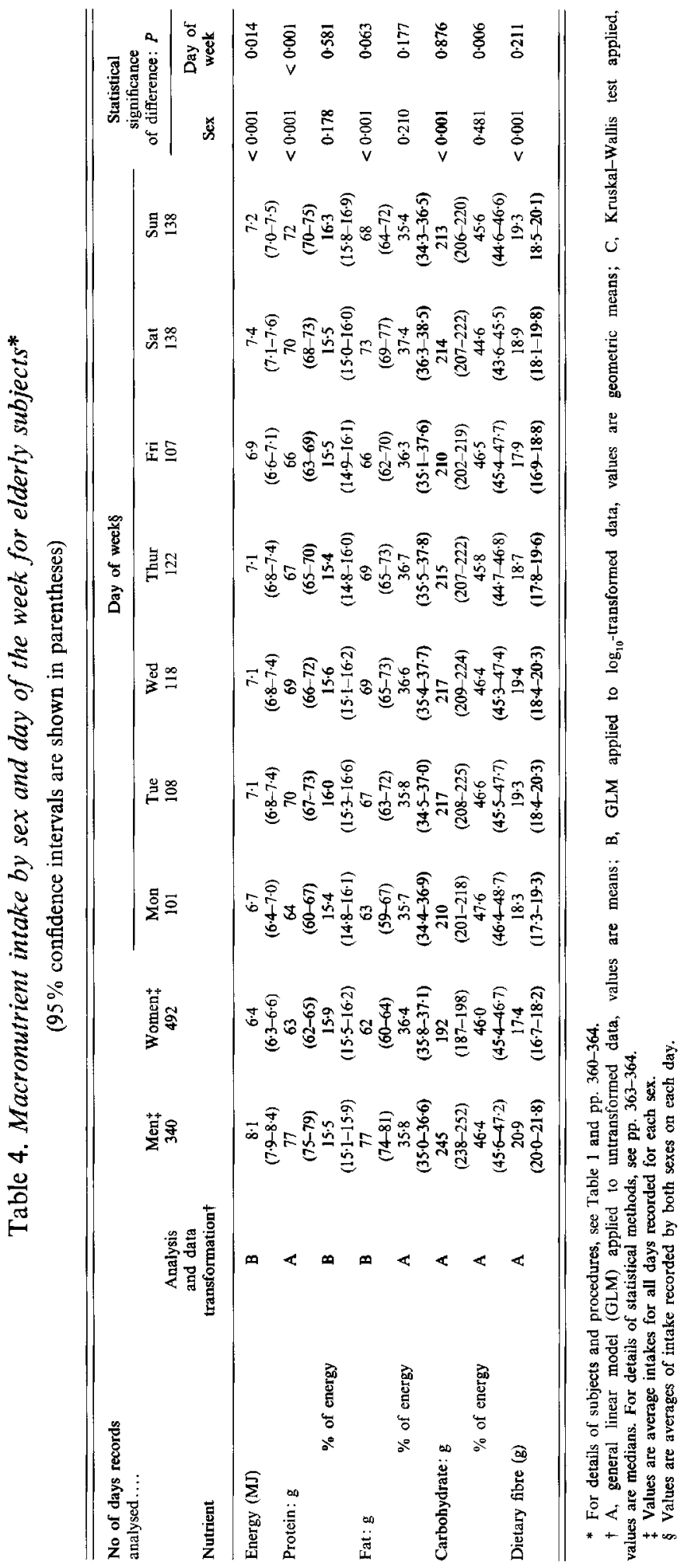




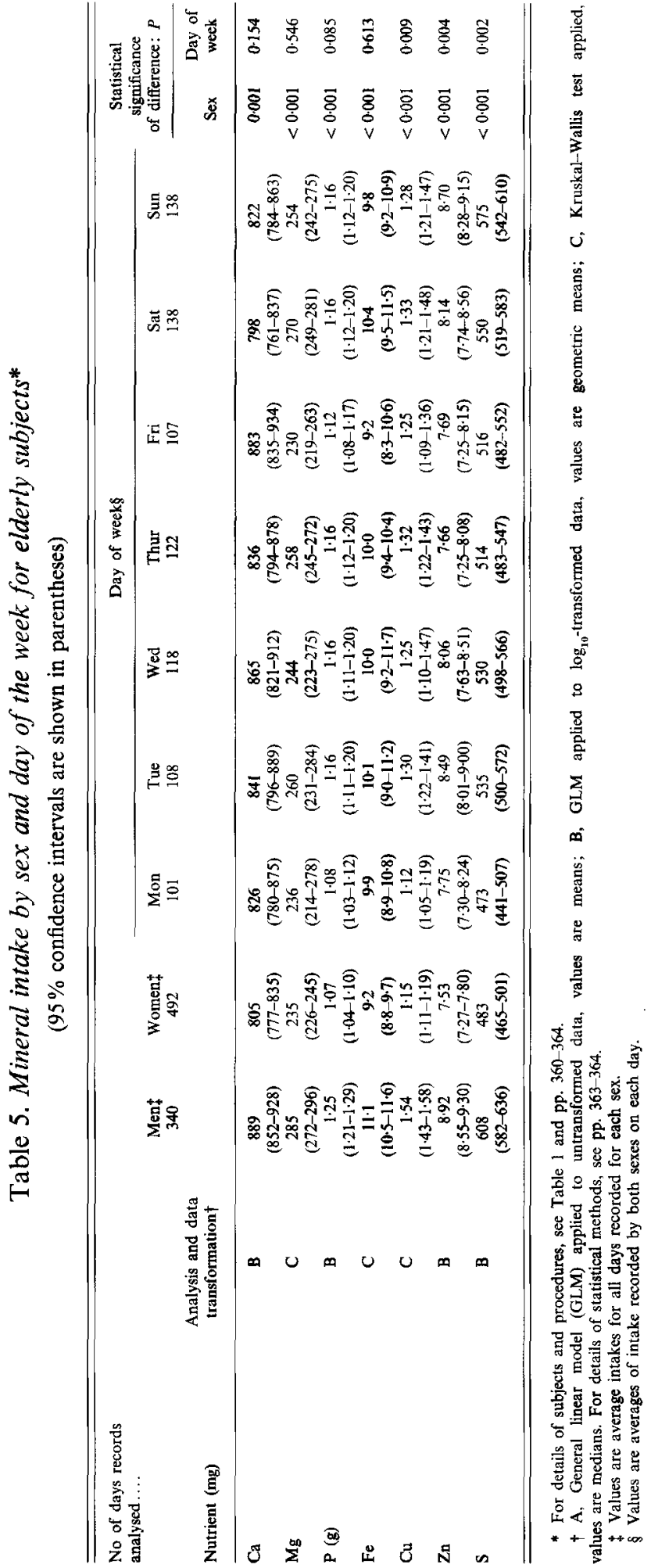




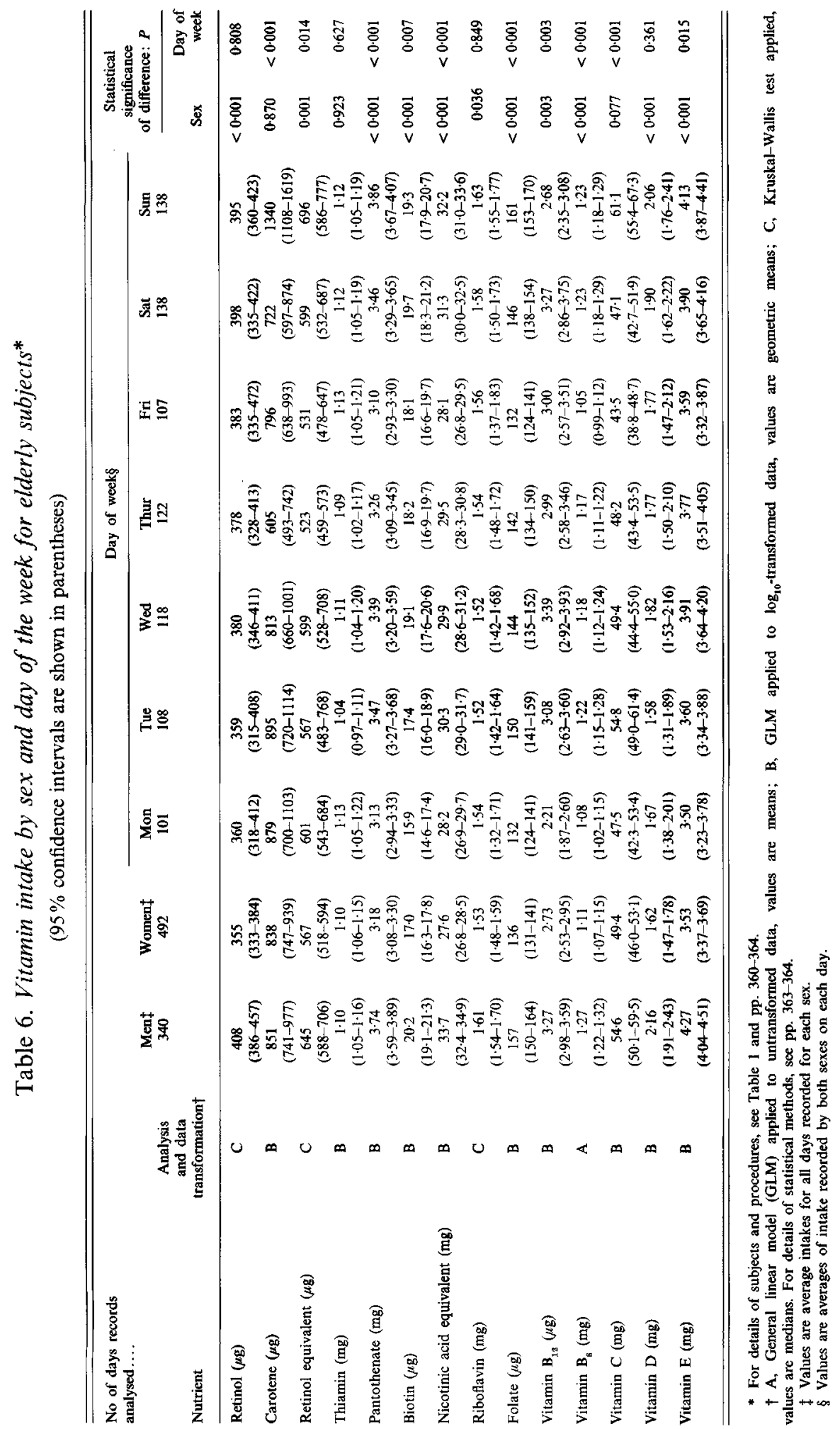




\section{DISCUSSION}

The population recruited for the present study can be considered as a reasonably representative sample of the free-living elderly in this provincial city. It was more difficult to recruit subjects from the older age-groups and the final sample still shows some shortfall in subjects aged over 80 years compared with the Office of Population Censuses and Surveys (OPCS ; personal communication) estimates for this area, despite efforts to redress the balance as described previously (p. 360). However, it is likely that the study subjects reflect more closely the age balance of those living independently, as the OPCS (1990) estimates would have included people living in homes for the elderly. Social classes IV and $\mathrm{V}$ are underrepresented, as is common in research populations of this type, probably due to better participation rates by the higher social classes. The proportion of subjects aged over 75 years who lived alone is less than that quoted in the General Household Survey 1991 (OPCS, 1993), but their eating pattern was the same as those who lived with other people, with the highest intakes of vegetable-derived micronutrients on Sundays. The habit of many widowed elderly people of visiting their children for Sunday lunch may be responsible for the maintainance of the traditional eating pattern.

The proportions of men and women reporting no alcohol intake during the recording period appear to continue the trend seen in the Dietary and Nutritional Survey of British Adults (OPCS, 1990) where these rose between the ages of 25 and 64 years (from 17 to $21 \%$ in men and 29 to $38 \%$ in women).

Patterns of intake across the week of the young (age 68-73 years) and old (age 74-90 years) elderly groups were similar for all nutrients, and there was little difference in total intake of most nutrients by the two groups, although they were assessed at different times of the year. In industrial societies seasonal variations in food supply are minimized and seasonal fluctuations in nutrient intake are very small compared to those observed for daily intakes (Bingham, 1987; Gibson, 1990). The GLM analysis of variation due to day of the week was blocked by subject so in any event there should have been no confounding effect of seasonality. The pooling of the two groups added considerably to the power of the analysis.

Previously-published work which includes analysis of variation in intake with day of the week is sparse and is available only for younger adult groups. Beaton et al. $(1979,1983)$ found increased intakes of energy and some nutrients at weekends in women but not men in a study population of sixty sales and office workers. Gibson et al. (1985) found increased energy and micronutrient intakes at weekends in fourteen female university students but concluded that nutrient densities were the same on weekdays and weekends. These authors found no evidence of a sequence or training effect on reported food intake, an observation which is replicated in our study. Thomson et al. (1988) also found increased energy intake at weekends in 164 Scottish men, half of which could be accounted for by increased alcohol intake. De Castro (1991) reported from a study of the effects of social context on eating behaviour and food intake that subjects under 50 years of age ate more at weekends but that this was not the case for subjects aged over 50 years, who were also less likely to eat in company with others. All these studies have assumed that nutrient intakes are similar on Saturdays and Sundays and that all weekdays are equal.

In the present study increased consumption of meat and vegetables and many micronutrients, especially carotene, folate and vitamin $\mathrm{C}$, was observed on Sundays, an effect which was also present when these nutrients were analysed in terms of nutrient density (amount of nutrient per MJ energy intake). Intake of most micronutrients was similar on Tuesday, Wednesday, Thursday and Saturday. Total energy intake was highest on the two weekend days, in agreement with other published work. Monday and, to a lesser 
extent, Friday were days when lower intakes of energy and many other nutrients were found. The day-of-the-week differences in nutrient intake in our elderly study population cannot simply be explained by increased overall food intake at weekends as described in other studies, but appear to be due to variation in both amount and type of food eaten on different days of the week.

The consensus in most published work on the methodology of determination of food and nutrient intakes of populations is that weekend days and weekdays should be proportionately represented to avoid bias due to day-of-the-week variations (Tarasuk \& Beaton, 1992). We would go further and recommend that all days of the week be proportionately represented in studies of the elderly, as the results we report here indicate that intakes of several micronutrients in this age-group do not follow energy intake, but are also affected by variation in diet quality over the course of the week. Specifically, Saturdays and Sundays cannot be assumed to give equal estimates of intake, especially of vegetablederived micronutrients.

The authors would like to thank all the subjects who gave their time and cooperation for this study, the doctors of Gurney Court and Tuckswood Surgeries who allowed us to recruit their patients and use their premises, the practice staff who helped in many ways, and the dietary interviewers. Special thanks are due to Andrew Walker, Computer Group, Institute of Food Research, for his advice and assistance with data handling, and to Dr Gareth Janaczek, Mathematics Department, University of East Anglia, for statistical advice.

The analysis of the intake data reported in this paper was supported by a grant from the Ministry of Agriculture, Fisheries and Food.

\section{REFERENCES}

Beaton, G. H., Milner, J., Corey, P., McGuire, V., Cousins, M., Stewart, E., de Ramos, M., Hewitt, D., Grambsch, P. V., Kassim, N. \& Little, J. A. (1979). Sources of variance in 24-hour recall data: Implications for nutrition study design and interpretation. American Journal of Clinical Nutrition 32, 2546-2599.

Beaton, G. H., Milner, J., McGuire, V., Feather, T. E. \& Little J. A. (1983). Sources of variance in 24-hour dietary recall data: Implications for nutrition study design and interpretation. Carbohydrate sources, vitamins and minerals. American Journal of Clinical Nutrition 37, 986-995.

Bingham, S. A. (1987). The dietary assessment of individuals; methods, accuracy, new techniques and recommendations. Nutrition Abstracts and Reviews 57, 705-742.

Crawley, H. (1988). Food Portion Sizes. London: H.M. Stationery Office.

de Castro, J. (1991). Weekly thythms of spontaneous nutrient intake and meal pattern of humans. Physiology and Behaviour 50, 729-738.

Department of Health (1992a). The Health of Elderly People. Central Office Monitoring Unit Epidemiological Overview Series, vol. 1. London: H.M. Stationery Office.

Department of Health (1992b). The Nutrition of Elderly People. Report on Health and Social Subjects No. 43. London: H.M. Stationery Office.

Gibson, R., Gibson, I. \& Kitching, J. (1985). A study of inter- and intra-subject variability in seven day weighed dietary intakes with particular emphasis on trace elements. Biological Trace Element Research 8, 79-91.

Gibson, R. S. (1990). Principles of Nutritional Assessment. Oxford: Oxford University Press.

Holland, B., Unwin, I. D. \& Buss, D. H. (1988). Cereals and Cereal Products. 3rd Supplement to McCance and Widdowson's The Composition of Foods, 4th ed. Cambridge: Royal Society of Chemistry/Ministry of Agriculture, Fisheries and Food.

Holland, B., Unwin, I. D. \& Buss, D. H. (1989). Milk and Milk Products. 4th Supplement to McCance and Widdowson's The Composition of Foods, 4th ed. Cambridge: Royal Society of Chemistry/Ministry of Agriculture, Fisheries and Food.

Office of Population Censuses and Surveys (1987). General Household Survey 1985. OPCS Series GHS no. 15. London: H.M. Stationery Office.

Office of Population Censuses and Surveys (1990). Dietary and Nutritional Survey of British Adults. London: H.M. Stationery Office.

Office of Population Censuses and Surveys (1993). General Household Survey 1991. OPCS Series GHS no. 22. London: H.M. Stationery Office. 
Paul, A. A. \& Southgate, D. A. T. (1978). McCance and Widdowson's The Composition of Foods, 4 th ed. London: H.M. Stationery Office.

Tan, S. P., Wenlock, R. W. \& Buss, D. H. (1985). Immigrant Foods. The 2nd Supplement to McCance and Widdowson's The Composition of Foods. London: H.M. Stationery Office.

Tarasuk, V. \& Beaton, G. H. (1992). Statistical estimation of dietary parameters: implications of patterns in within-subject variation - a case study of sampling strategies. American Journal of Clinical Nutrition 55, 22-27.

Thomson, M., Elton, R., Fulton, M., Brown, S., Wood, D. \& Oliver, M. (1988). Individual variation in the dietary intake of a group of Scottish men. Journal of Human Nutrition and Dietetics 1, 47-57.

Wiles, S. J., Nettleton, P. A., Black A. E. \& Paul, A. A. (1980). The nutrient content of some cooked dishes eaten in Britain: Supplementary food composition table. Journal of Human Nutrition 34, 189-223. 